\title{
Patch Cramming Reveals the Mechanism of Long-Term Suppression of Cyclic Nucleotides in Intact Neurons
}

\author{
Bhavya Trivedi ${ }^{1}$ and Richard H. Kramer ${ }^{1,2}$ \\ 1 Department of Molecular and Cellular Pharmacology, University of Miami School of Medicine, Miami, Florida 33101, and \\ ${ }^{2}$ Department of Molecular and Cell Biology, University of California, Berkeley, Berkeley, California 94720
}

To understand cyclic nucleotide dynamics in intact cells, we used the patch-cramming method with cyclic nucleotide-gated channels as real-time biosensors for cGMP. In neuroblastoma and sympathetic neurons, both muscarinic agonists and nitric oxide (NO) rapidly elevate cGMP. However, muscarinic agonists also elicit a long-term (2 hr) suppression (LTS) of subsequent cGMP responses. Muscarinic agonists elevate cGMP by triggering $\mathrm{Ca}^{2+}$ mobilization, which activates NO synthase to produce NO, leading to the activation of soluble guanylate cyclase (sGC). Here we examine the mechanism of LTS. Experiments using direct intracellular cGMP injection demonstrate that enhancement of phosphodiesterase (PDE) activity, rather than depression of SGC activity, is responsible for LTS. Biochemical measurements show that both cGMP and cAMP content is suppressed, consistent with the involvement of a nonselective PDE. Application of pharmacological agents that alter $\mathrm{Ca}^{2+}$ mobilization from intracellular stores and experiments involving injection of the $\mathrm{Ca}^{2+}$ chelator BAPTA show that $\mathrm{Ca}^{2+}$ mobilization is necessary and sufficient for LTS induction but also show that LTS maintenance is $\mathrm{Ca}^{2+}$-independent. Protein phosphatase injection reverses LTS, and specific inhibitors of $\mathrm{Ca}^{2+}$ /calmodulin kinase II (CaMKII) prevent induction and inhibit maintenance. The switch between the $\mathrm{Ca}^{2+}$ dependence of LTS induction to the $\mathrm{Ca}^{2+}$ independence of LTS maintenance is consistent with CaMKII autophosphorylation, similar to proposed mechanisms of hippocampal long-term potentiation. Because the molecular machinery underlying LTS is common to many cells, LTS may be a widespread mechanism for long-term silencing of cyclic nucleotide signaling.

Key words: sympathetic neuron; neuroblastoma; cGMP; nitric oxide; CaMKII; cyclic nucleotide-gated channel; synaptic plasticity
Cyclic nucleotides (cAMP and cGMP) play a central role in synaptic plasticity. The nitric oxide (NO)/cGMP pathway may be crucial for long-term depression (LTD) in cerebellar Purkinje neurons (Lev-Ram et al., 1997), and both NO/cGMP and cAMP have been implicated in long-term potentiation (LTP) in the hippocampus (Arancio et al., 1995; Nicoll and Malenka, 1995). Despite the growing awareness of the involvement of cyclic nucleotides in synaptic plasticity, relatively little is known about the intracellular dynamics of cAMP or cGMP.

We recently described a method for real-time detection of free cGMP in single living cells by "patch cramming," in which CNG channels engineered to be especially sensitive and selective for cGMP are used as biosensors (Trivedi and Kramer, 1998). A patch pipette is used to excise a membrane patch from a Xenopus oocyte expressing a high density of cGMP detector channels. The detector patch is calibrated with known concentrations of cGMP and then "crammed" into a recipient N1E-115 neuroblastoma cell. The activity of the channels provides a continuous quantitative measure of cGMP concentration in the recipient cell.

N1E-115 neuroblastoma cells are related biochemically and physiologically to sympathetic neurons (Kimhi et al., 1976). We found that NO donors or muscarinic agonists elevate cGMP in

\footnotetext{
Received May 1, 2002; revised July 19, 2002; accepted July 26, 2002.

This work was supported by grants from National Institutes of Health and the American Heart Association. We thank Michael Vendiola and Daryll Discher for assistance with sympathetic neurons, Andrew Rosendahl for help with calcium measurements, and Tom Soderling for providing CaM-KIINtide.

Correspondence should be addressed to Dr. Richard H. Kramer, 121 Life Sciences Addition, Department of Molecular and Cell Biology, University of California, Berkeley, Berkeley, CA 94720-3200. E-mail: rhkramer@uclink4.berkeley.edu. Copyright (C) 2002 Society for Neuroscience $0270-6474 / 02 / 228819-08 \$ 15.00 / 0$
}

both cells (Trivedi and Kramer, 1998). There was no decrement of the cGMP response generated by NO, whereas cGMP transients diminished dramatically with repeated activation of muscarinic receptors. Surprisingly, muscarinic activation also suppressed subsequent cGMP responses to NO for at least $30 \mathrm{~min}$. Biochemical measurements confirmed that this long-term suppression (LTS) of cGMP occurs in both cell types and persists for up to $2 \mathrm{hr}$. Thus muscarinic activation not only elevates cGMP in the short term, it also depresses resting cGMP and prevents NO-elicited transients in the long term.

The biochemical steps linking muscarinic receptors to cGMP elevation have been studied extensively and are conserved in sympathetic neurons and neuroblastoma cells. Activation of muscarinic receptors leads to G-protein-mediated inositol triphosphate $\left(\mathrm{IP}_{3}\right)$ production and subsequent $\mathrm{Ca}^{2+}$ release from intracellular stores (Briggs et al., 1985; Thompson et al., 1995). Elevated cytoplasmic $\mathrm{Ca}^{2+}$ activates NO synthase (NOS) to produce NO (Forstermann et al., 1990; Wotta et al., 1998), which then stimulates cGMP production by soluble guanylate cyclase (sGC) (Hu and El-Fakahany, 1993).

The purpose of this study is to determine the mechanism of LTS. Because NO directly activates sGC, the suppression of cGMP responses elicited by NO donors must result from the regulation of enzymes involved in cGMP metabolism, far downstream from the muscarinic receptor itself. These include sGC, which synthesizes cGMP, and phosphodiesterase (PDE), which degrades cGMP. How do muscarinic agonists initiate LTS? Because cGMP itself does not produce LTS, some upstream intermediate in the muscarinic signaling cascade must feed forward to regulate sGC and/or PDE. How is LTS maintained for hours 
after brief (1 min) muscarinic stimulation? The long duration of LTS suggests that the regulation of these enzymes is mediated by some covalent modification, such as phosphorylation. Via patch cram measurements, pharmacological treatments, and direct injection of cGMP and enzyme inhibitors, we answer these questions and elucidate the mechanism of LTS.

\section{MATERIALS AND METHODS}

Cell culture. N1E-115 neuroblastoma cells (Amano et al., 1972) were maintained in DMEM with $10 \% \mathrm{FBS}$ at $37^{\circ} \mathrm{C}$ with $10 \% \mathrm{CO}_{2}$. Cells were grown to $70 \%$ confluence on poly-L-lysine-coated glass coverslips before being treated with $2 \%$ DMSO for $10-21 \mathrm{~d}$ to induce differentiation, which is characterized by the appearance of processes, voltage-gated ionic currents, and action potentials (Kimhi et al., 1976; Moolenaar and Spector, 1978). Culture medium was exchanged every $2-3 \mathrm{~d}$, and cells were used in passages $5-12$.

Patch cramming. A cDNA clone encoding RONS2, a chimeric CNG channel, was used for in vitro transcription of cRNA (Goulding et al., 1994). The cRNA was injected into Xenopus oocytes at high concentrations $(50 \mathrm{nl} /$ oocyte at $0.2-0.3 \mathrm{ng} / \mathrm{nl})$ to obtain high levels of expression. After 2-7 d the vitelline membrane was removed, and the denuded oocytes were placed in the experimental chamber with neuroblastoma cells, which were used as recipient cells in all patch-cramming experiments. Glass patch pipettes (2-4 M $\Omega$ ) were filled with a solution containing (in $\mathrm{mm}$ ): $100 \mathrm{~K}$-gluconate, $20 \mathrm{KCl}$, and $10 \mathrm{Na}$-HEPES, pH 7.4. This also served as the cGMP calibration solution. After the formation of a gigaohm seal the inside-out patches were excised, and the patch pipette was placed in the outlet of a $1 \mathrm{~mm}$ in diameter tube for the application of four to five concentrations of cGMP $(0.5-100 \mu \mathrm{M})$. Current responses through $\mathrm{CNG}$ channels were obtained with a Warner PC-505 patch clamp, filtered at $1 \mathrm{kHz}$, digitized, stored, and later analyzed on a computer. To confirm successful impalement of recipient neuroblastoma cells and to allow voltage clamp, we used a second pipette containing nystatin for perforated patch clamp (Horn and Marty, 1988; Trivedi and Kramer, 1998).

After access resistance declined to $<60 \mathrm{M} \Omega$, the membrane potential was held under voltage clamp $(-50 \mathrm{mV})$, and the neuroblastoma cell was impaled with the detector patch electrode. Successful impalement was confirmed by the appearance of an offset in the oocyte patch current caused by the potential difference across the neuroblastoma cell membrane. During the calibration the oocyte patch was held at $-75 \mathrm{mV}$, and $350 \mathrm{msec}$ in duration voltage pulses to $0 \mathrm{mV}$ were applied at $2 \mathrm{~Hz}$. Resulting currents were measured to calculate conductance changes in response to cGMP. After insertion into the recipient cell the detector patch was held at $-25 \mathrm{mV}$ so that the total voltage difference across the detector patch was the same as during the calibration $(-75 \mathrm{mV})$. Changes in intracellular cGMP were recorded as changes in detector patch conductance.

Solutions were superfused continuously over the neuroblastoma cell. The bath solution contained (in $\mathrm{mM}$ ): $120 \mathrm{NaCl}, 2.5 \mathrm{KCl}, 1 \mathrm{MgCl}_{2}, 2$ $\mathrm{CaCl}_{2}, 5 \mathrm{Na}-\mathrm{HEPES}$, and $10 \mathrm{D}$-glucose, $\mathrm{pH}$ 7.4. All pharmacological agents including cGMP, nystatin, IBMX, BAPTA (Sigma, St. Louis, MO), vinpocetine, quazinone, zaprinast, erthro-9-(2-hydroxy-3-nonyl) adenine (EHNA) (Biomol, Plymouth Meeting, PA), RO-20-1724, YC-1 (Alexis Pharmaceuticals, San Diego, CA), KN-62, 7-NI, NOR-4 (Calbiochem, La Jolla, CA), oxotremorine-M (oxo-M; Research Biochemicals, Natick, MA), pCPT-cGMP (Biolog, Hayward, CA), and ODQ (Tocris Cookson, Ballwin, MO) were prepared first as concentrated stock solutions in water or DMSO. The final concentration of DMSO in working solutions did not exceed $0.1 \%$ and had no effect on the cGMP detector patch. As reported previously (Trivedi and Kramer, 1998), the CNG channels in the detector patch had no direct sensitivity to the pharmacological agents that were used in this study, including NOR-4, oxo-M, YC-1, IBMX, BAPTA, and thapsigargin. These agents did not activate the CNG channels directly and had no effect on their measured sensitivity to cGMP. NOR-4 was the NO donor used in all patchcramming experiments because of its long half-life $(60 \mathrm{~min})$. When individual applications of NOR-4 were used $>20$ min apart on the same cells, a new batch of NOR-4 solution was prepared and loaded into the perfusion apparatus. Variability among measurements is expressed as the means \pm SEM.

Alkaline phosphatase, as well as peptide inhibitors of protein kinases, was prepared in distilled water at $10 \times$ the final cytoplasmic concentration and was pressure injected into recipient cells with a Picospritzer
(General Valve, Fairfield, NJ). In some experiments we used Ultrapure alkaline phosphatase, free of detectable DNase, RNase, or protease activity (Worthington Biochemical, Freehold, NJ). Protein kinase C inhibitor peptide 19-31 (PKC-IP; House and Kemp, 1987) and autocamtide-2 related inhibitory peptide (AIP) (Ishida et al., 1995) were obtained from Calbiochem. CaM-KIINtide (Chang et al., 1998) was kindly provided by Dr. Thomas Soderling (Vollum Institute, Portland, OR).

Sympathetic neuron cultures. Superior cervical ganglia were dissected from $1-3 \mathrm{~d}$ postnatal rats, desheathed, incubated in collagenase $(1 \mathrm{mg} / \mathrm{ml}$, $15 \mathrm{~min}$ ), triturated, and plated onto poly-L-lysine-coated plastic culture dishes at approximately one ganglion per dish. Cells were maintained in DMEM with $10 \%$ horse serum, $1 \%$ penicillin/streptavidin, $0.5 \mathrm{~mm}$ glutamine, and $50 \mathrm{ng} / \mathrm{ml}$ nerve growth factor (7S). Cultures were kept at $37^{\circ} \mathrm{C}$ in an incubator with $10 \% \mathrm{CO}_{2}$. The medium was changed twice per week, and the neurons were allowed to mature for 8-10 d.

Biochemical measurements of cAMP. cAMP was assayed by using the Biotrak enzyme immunoassay system (Amersham Biosciences, Arlington Heights, IL). Cells were treated with agonist, and reactions were terminated by applying $6 \%(\mathrm{w} / \mathrm{v})$ trichloroacetic acid. Cells were scraped into Microfuge tubes and centrifuged; the supernatant was washed with diethyl ether before cAMP was determined. The pellet was used for assaying total protein content (Bio-Rad Protein Assay Kit II, Hercules, CA).

\section{RESULTS}

\section{Which metabolic enzyme underlies LTS?}

We began by investigating the possibility that stimulation with a muscarinic agonist (oxo-M) induces LTS by generating some molecule that "scavenges" $\mathrm{NO}$ and prevents it from activating sGC, thereby suppressing cGMP production. However, we find that LTS applies not only to cGMP transients elicited by NO donors but also to responses elicited by YC-1, a specific sGC activator that acts in an NO-independent manner (Wu et al., 1995) (Fig. 1A). Application of YC-1 without the previous induction of LTS effectively elevates cGMP (Fig. $1 B$ ). Hence LTS is not specific to $\mathrm{NO}$, discounting the possibility that the generation of an NO scavenger is the mechanism.

Does a decrease in sGC activity underlie LTS? Previously, we showed that isobutyl methylxanthine (IBMX), a PDE inhibitor (Beavo et al., 1982), elicits a rise in cGMP (Trivedi and Kramer, 1998), suggesting that in the absence of degradation there is significant basal sGC activity. We also showed that responses to saturating IBMX $(100 \mu \mathrm{M})$ are not reduced after LTS induction, indicating that basal guanylate cyclase activity is not inhibited. Is the guanylate cyclase enzyme responsible for basal cGMP production the same as the enzyme that underlies NO-elicited GMP production? cGMP transients in response to IBMX are blocked by a sGC inhibitor (Garthwaite et al., 1995), ODQ (1H$[1,2,4]$ oxadiazolo [4,3-a]quinoxalin-1-one; $n=4)$, or a NOS inhibitor (Silva et al., 1995), 7-nitro indazole (7-NI; $n=3$ ), both of which prevent cGMP transients in response to oxo-M (Trivedi and Kramer, 1998). Hence both sGC and NOS are required not only for muscarinic responses but also for basal cGMP production. Taken together, these results are inconsistent with inhibition of sGC during LTS and focus our attention on PDE.

To test directly whether PDE activity is increased during LTS, we bypassed $\mathrm{sGC}$ by pressure-injecting cGMP into recipient cells while measuring intracellular cGMP with the detector patch. The cGMP concentration in the injection pipette and the duration of pressure injection were adjusted to produce peak intracellular cGMP elevations of $<5 \mu \mathrm{M}$. Before LTS the injection of cGMP rapidly $(<1 \mathrm{sec})$ activated the detector patch, and the cGMP elevation decayed very slowly over $10 \mathrm{~min}$ (Fig. $2 A ; n=6$ ), suggesting the slow degradation of cGMP. After LTS induction the cGMP injection produced smaller responses that decayed 

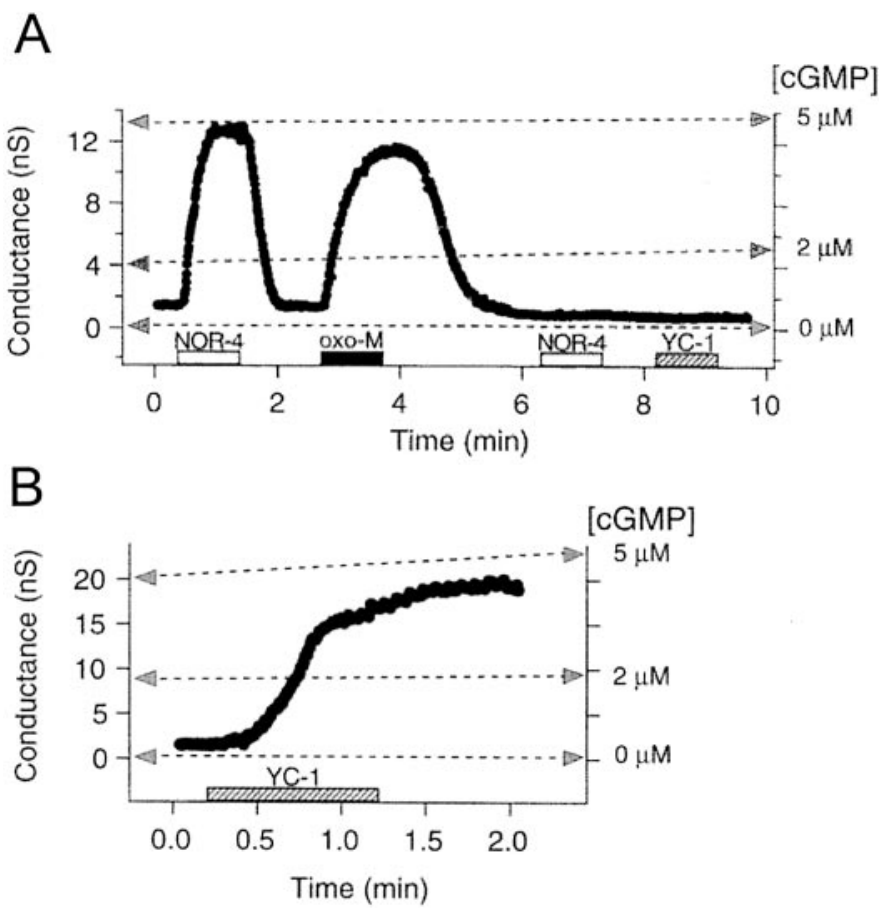

Figure 1. LTS of NO-dependent and NO-independent elevations of cGMP. $A$, Patch-cram measurement of cGMP in a N1E-115 cell showing that induction of LTS with a muscarinic agonist $(10 \mu \mathrm{M}$ oxo-M) results in suppression of cGMP responses both to an NO donor (100 $\mu \mathrm{M}$ NOR-4) and to a NO-independent activator of sGC (100 $\mu \mathrm{M}$ YC-1). $B$, In the absence of LTS induction the application of $100 \mu \mathrm{M}$ YC-1 produces a large increase in cGMP. For this and subsequent patch-cramming figures the gray triangles on the left ordinate represent cGMP calibrations before cramming (precalibration), and those on the right represent cGMP calibrations after the detector patch is withdrawn from the recipient cell (postcalibration).

much more rapidly ( $<1 \mathrm{~min} ; n=9$ ). To confirm that enhanced PDE activity is responsible for the dramatically accelerated decay, we injected cGMP in the presence of IBMX after inducing LTS (Fig. 2B). With IBMX present the cGMP injections resulted in large, long-lasting responses indistinguishable from those elicited before LTS induction. In this experiment $10 \mu \mathrm{M}$ ODQ was included to block all sGC activity irreversibly and prevent IBMX itself from elevating cGMP. These results conclusively demonstrate that the enhancement of PDE activity underlies LTS.

Some types of PDE are specific for cGMP or cAMP, but others have broad substrate specificities and can hydrolyze either cyclic nucleotide (Beavo, 1995). To test whether the PDE(s) upregulated during LTS also can hydrolyze cAMP, we used an enzyme immunoassay that is specific for cAMP. Figure $3 A$ shows that elevations of cAMP in cultures of mammalian sympathetic neurons, elicited by vasoactive intestinal peptide (VIP), are suppressed after oxo-M treatment. As a control, repeated applications of VIP elicited reproducible elevations of cAMP (Fig. 3B). Suppression of cAMP after muscarinic activation also was observed in similar experiments in neuroblastoma cells, and the suppression persisted for at least $30 \mathrm{~min}$ (data not shown). Thus LTS applies both to cGMP and cAMP, further supporting the conclusion that the enhanced activity of one or more PDEs is responsible.

To investigate which PDEs are important for regulating cGMP levels and LTS, we applied various selective inhibitors at concentrations that fully block specific families of PDEs. Neither zapri-
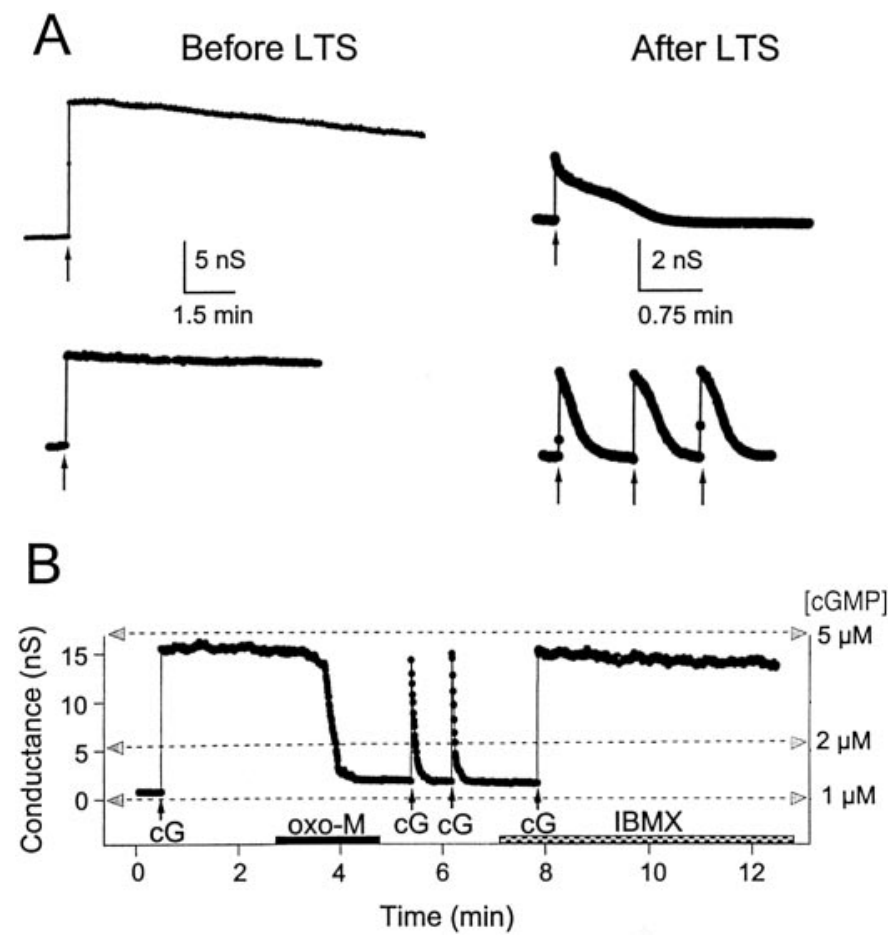

Figure 2. Direct injection of cGMP while patch cramming reveals faster degradation of cGMP by PDE after LTS induction. $A$, cGMP was injected with a glass pipette containing $500 \mu \mathrm{M}$ cGMP at the times indicated by the arrows. After LTS induction the cGMP injections produce smaller cGMP elevations that decay much more rapidly. Note the different time and amplitude scales before and after LTS induction. $B$, Continuous record showing changes in detector patch responses resulting from cGMP $(c G)$ injections and LTS induction. After $\sim 40 \mathrm{sec}$ delay the oxo-M triggered a fall in cGMP concentration and markedly accelerated the recovery from subsequent cGMP injections. IBMX $(10 \mu \mathrm{M})$ completely inhibited the effect of oxo-M. ODQ $(10 \mu \mathrm{M})$ was included throughout to block sGC activity.

nast $(10 \mu \mathrm{M})$, selective for cGMP-specific PDEs (PDE-5) (Gillespie and Beavo, 1989), nor RO-20-1724 (100 $\mu \mathrm{M})$, selective for cAMP-specific PDEs (PDE-4) (Tanner et al., 1986), elevated basal cGMP $(n=3)$, suggesting that the PDEs involved in LTS are not PDE-4 or PDE-5. Likewise, neither $100 \mu \mathrm{M}$ vinpocetine (Ahn et al., 1989) nor $10 \mu \mathrm{M}$ EHNA (Mery et al., 1995), selective for $\mathrm{Ca}^{2+} /$ calmodulin-dependent PDEs (PDE-1) and cGMPstimulated PDE (PDE-2), respectively, elevated cGMP $(n=3)$. Quazinone $(20 \mu \mathrm{M})$, an inhibitor of cGMP-inhibited PDEs (PDE-3) (Holck et al., 1984), did elevate cGMP to the same extent as did saturating IBMX (100 $\mu \mathrm{M} ; n=3)$, a nonselective PDE inhibitor. Hence the upregulation of PDE-3 may underlie LTS, but it is also possible that pharmacologically uncharacterized PDEs in other families or even a novel form of PDE is responsible.

\section{How is LTS initiated?}

Muscarinic agonists transiently elevate cGMP and subsequently cause LTS. Our results suggest that some intermediate in the muscarinic signaling cascade feeds forward to enhance PDE activity. Similarly, several other transmitters (angiotensin, bradykinin, and neurotensin) initially elevate cGMP but subsequently induce LTS ( $n=2-3$ for each transmitter). These transmitters may act via a common signaling cascade involving the G-protein-mediated production of $\mathrm{IP}_{3}, \mathrm{Ca}^{2+}$ release from internal stores, $\mathrm{Ca}^{2+}$ activation of NOS, production of NO, 


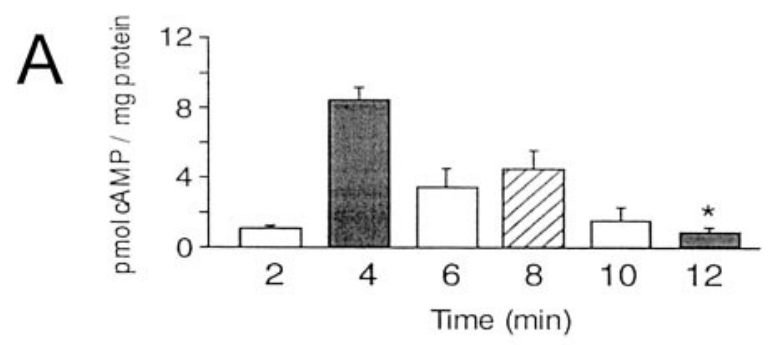

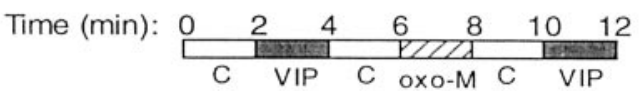

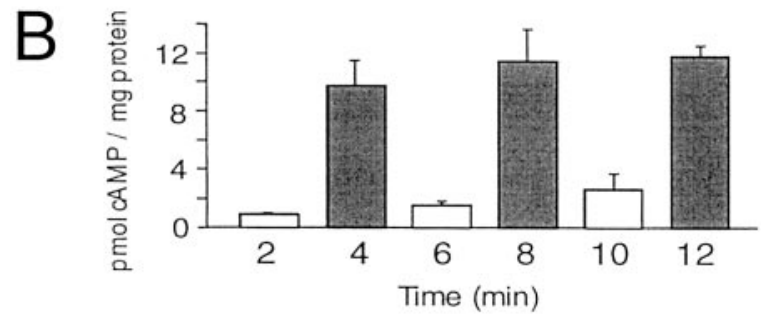

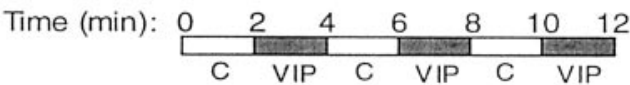

Figure 3. Enzyme immunoassay measurements of cAMP in rat sympathetic neurons demonstrate that cAMP is suppressed after muscarinic activation. Cells were lysed at each of the times indicated (see timeline) and assayed for total cAMP and protein $(n=4)$. Vasoactive intestinal peptide $(V I P)$ was used to elevate cAMP. Timelines show the two treatment protocols: $A$, VIP/oxo-M/VIP; $B$, VIP/VIP/VIP. After oxo-M treatment the VIP-induced elevation of cAMP was reduced significantly ( $p<0.05$, paired $t$ test) as compared with before oxo-M treatment.

and activation of sGC. Because prolonged application of NO alone does not cause LTS (Trivedi and Kramer, 1998), the signal responsible for inducing LTS must be upstream of NO. Because $\mathrm{Ca}^{2+}$ is an essential component of signaling for each of these transmitters, we asked whether it is crucial for inducing LTS.

To test whether a rise in intracellular $\mathrm{Ca}^{2+}$ is sufficient for initiating LTS, we used the $\mathrm{Ca}^{2+}$ ionophore ionomycin. Figure $4 A$ shows that ionomycin, which raises cytoplasmic $\mathrm{Ca}^{2+}$ even in the absence of external $\mathrm{Ca}^{2+}$ (Albert and Tashjian, 1986; our unpublished observations), produces a rise in cGMP and induces LTS $(n=3)$. Depletion of intracellular $\mathrm{Ca}^{2+}$ stores by pretreatment with thapsigargin prevented the rise in cGMP in response to oxo-M and prevented the induction of LTS $(n=3$; Fig. $4 B)$. These findings suggest that $\mathrm{Ca}^{2+}$ mobilization is both necessary and sufficient for induction of LTS.

To test further the role of $\mathrm{Ca}^{2+}$ in LTS, we pressure-injected BAPTA into the recipient neuroblastoma cell to chelate intracellular $\mathrm{Ca}^{2+}$. When BAPTA was injected before the application of oxo-M, the muscarinic agonist was unable to elevate cGMP, and subsequent NO responses were not suppressed (Fig. $5 A$ ), strongly supporting the idea that $\mathrm{Ca}^{2+}$ is necessary for induction. A different result was obtained when BAPTA was injected after LTS was initiated (Fig. 5B). Once LTS is triggered, BAPTA is unable to reverse the suppression of cGMP and restore responses to NO or muscarinic agonists, suggesting that LTS can be maintained even in the absence of intracellular $\mathrm{Ca}^{2+}$. Moreover, the time course of LTS (up to $2 \mathrm{hr}$ ) is much longer that the duration

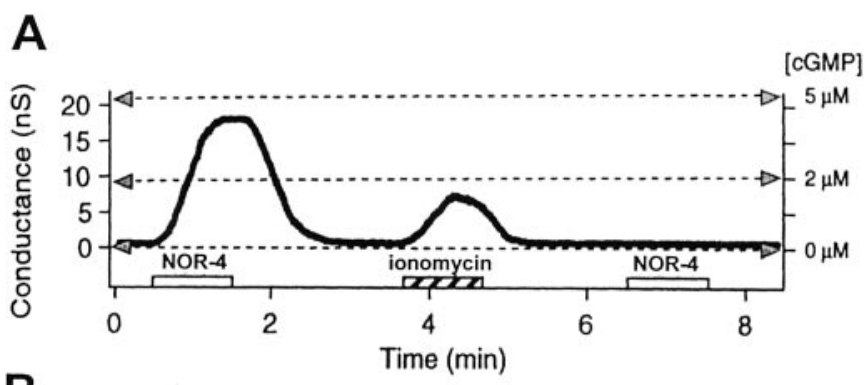

B

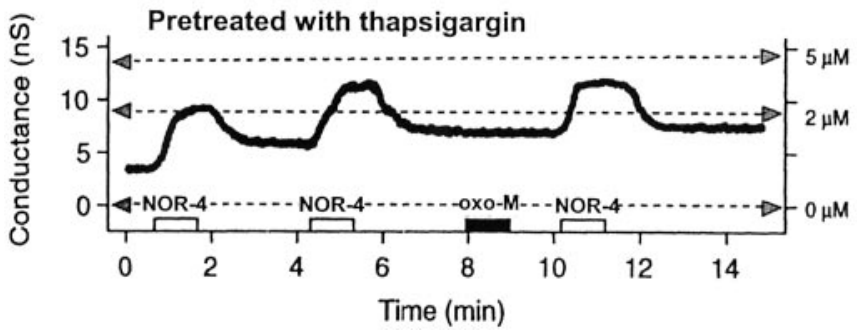

Figure 4. $\mathrm{Ca}^{2+}$ mobilization is necessary and sufficient for LTS induction but not maintenance. $A$, Application of ionomycin $(2 \mu \mathrm{M})$, a $\mathrm{Ca}^{2+}$ ionophore, elicits a cGMP response and results in suppression of the subsequent NO-induced elevation of cGMP. $B$, Pretreatment with thapsigargin $(300 \mathrm{nM})$ for $30 \mathrm{~min}$ to deplete internal calcium stores prevents cGMP elevation and LTS induction by oxo-M.

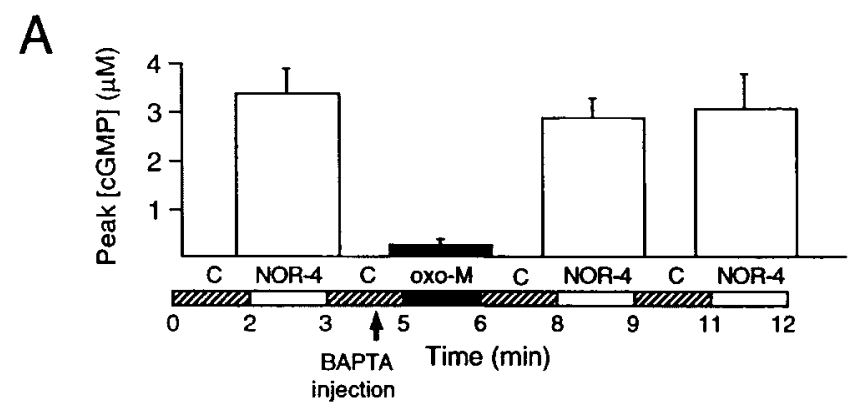

B

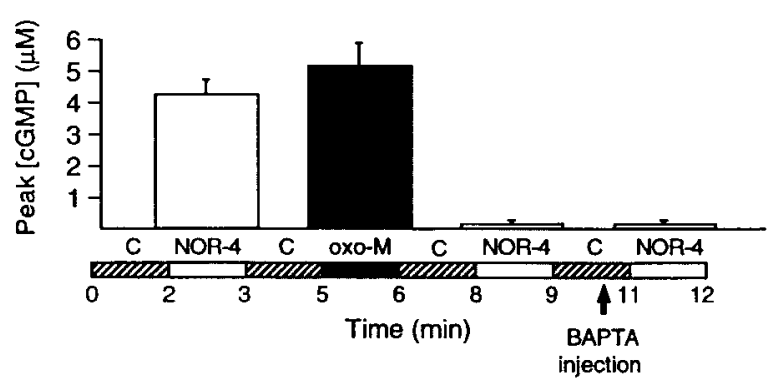

Figure 5. BAPTA injection blocks LTS initiation but not LTS maintenance. Summary of results from patch-cramming experiments in which BAPTA was injected into recipient cells before $(A)$ and after $(B)$ LTS was induced. Agonists were applied in the sequence indicated by the timeline below each graph. Each column represents the peak concentration of cGMP during the agonist application $\pm \operatorname{SEM}(n=3)$, which was calculated from the Hill fit to cGMP precalibrations. BAPTA $(500 \mu \mathrm{M}$ in pipette) was injected with $10 \mathrm{msec}$ pressure pulses.

of the $\mathrm{Ca}^{2+}$ transient resulting from muscarinic activation, which in $\mathrm{Ca}^{2+}$ imaging experiments appears to be $<60 \mathrm{sec}(n=3$; data not shown), in agreement with previous studies (Mathes and Thompson, 1994). Hence the maintenance of LTS is $\mathrm{Ca}^{2+}$-independent. 


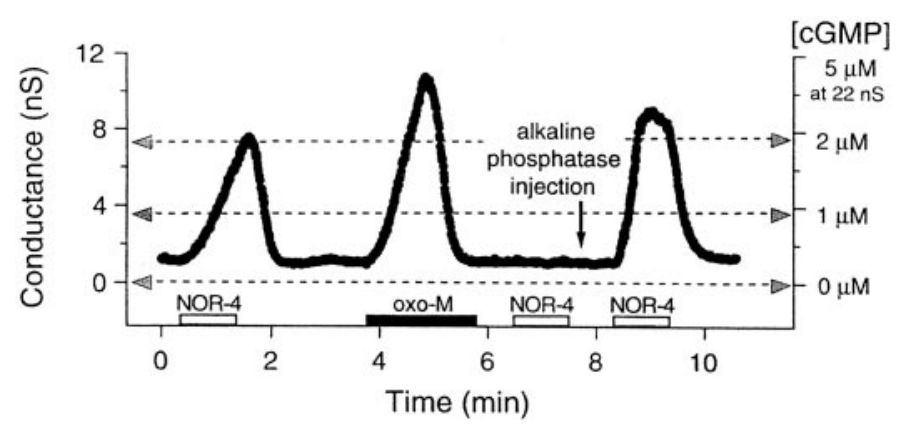

Figure 6. Alkaline phosphatase injection reverses LTS maintenance. After the induction of LTS with oxo-M $(10 \mu \mathrm{M})$, the pressure injection of alkaline phosphatase $(400 \mathrm{U} / \mathrm{ml}$ in injection pipette) eliminates LTS maintenance and restores the cGMP response to NOR-4.

\section{How is LTS maintained?}

The persistence of LTS for up to $2 \mathrm{hr}$ is consistent with a covalent modification of enzymes of cGMP metabolism, such as a change in phosphorylation state. If phosphorylation of PDE or some PDE regulatory protein is responsible for maintaining LTS, then increasing dephosphorylation might reverse LTS. Indeed, injection of alkaline phosphatase reverses LTS and allows NO to elevate cGMP (Fig. 6). In fact, cGMP responses to NO were as large or larger than before LTS $(n=5)$, consistent with preexisting phosphorylation partly suppressing responses even before LTS induction. In two of these experiments we used an Ultrapure preparation of alkaline phosphatase to insure that LTS reversal did not arise from possible contaminants, such as proteases.

Several $\mathrm{Ca}^{2+}$-sensitive protein kinases in neuroblastoma and sympathetic neurons might be involved in maintaining LTS, including $\mathrm{Ca}^{2+} /$ calmodulin kinase II (CaMKII) and protein kinase $\mathrm{C}$ (PKC). CaMKII regulates transmitter metabolism in sympathetic neurons (Cahill and Perlman, 1987), and PKC contributes to internalization and desensitization of muscarinic receptors (Liles et al., 1986); hence both are candidates. Treatment of recipient neuroblastoma cells with $\mathrm{KN}-62$, a specific membranepermeant inhibitor of CaMKII (Tokumitsu et al., 1990), prevented the appearance of LTS $(n=4)$ but did not inhibit the rise in cGMP with muscarinic stimulation (Fig. $7 A$ ). Moreover, the injection of AIP, a specific psuedosubstrate peptide inhibitor of CaMKII (Ishida et al., 1995), before the application of oxo-M prevents the induction of LTS $(n=3)$ without preventing the muscarinic elevation of cGMP (Fig. $7 B$ ). In contrast, the injection of PKC-IP, a specific peptide inhibitor of the $\alpha$ and $\beta$ isoforms of PKC (House and Kemp, 1987), had no effect on the induction of LTS $(n=3$; Fig. $7 C)$. These results suggest a specific role for CaMKII in the induction of LTS.

Does CaMKII underlie the maintenance of LTS? After CaMKII is activated by elevated intracellular $\mathrm{Ca}^{2+}$, it undergoes autophosphorylation, which stabilizes the activation of the enzyme and renders it much less $\mathrm{Ca}^{2+}$-sensitive. Thus CaMKII acts as a bistable molecular switch (Lisman and Goldring, 1988) that is turned on by $\mathrm{Ca}^{2+}$. Our observations that LTS induction is $\mathrm{Ca}^{2+}$-dependent whereas maintenance is $\mathrm{Ca}^{2+}$-independent are consistent with the properties of CaMKII. To test the role of CaMKII in maintenance, we injected peptide inhibitors after the induction of LTS with oxo-M. The AIP peptide was only partly effective at reversing LTS, with the postinjection cGMP response to NO being $7 \pm 2 \%(n=3)$ as large as the response before LTS induction. However, the injection of "CaM-KIINtide," a highly

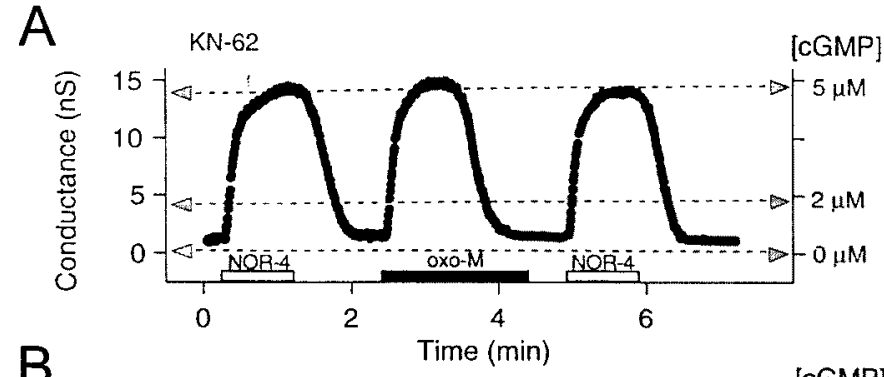

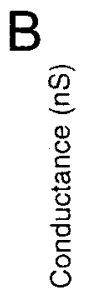

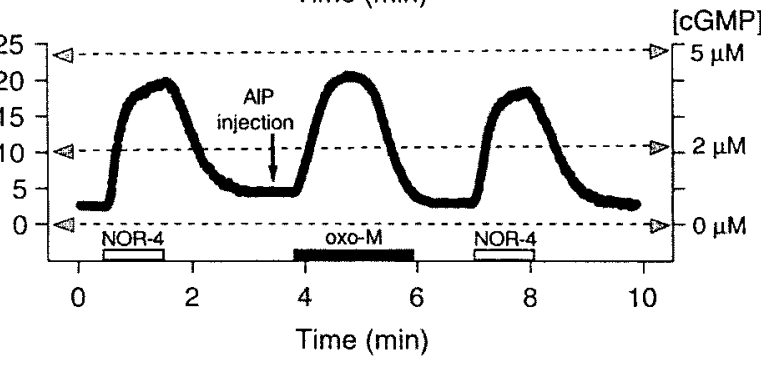

$\mathrm{C}$ [CGMP]

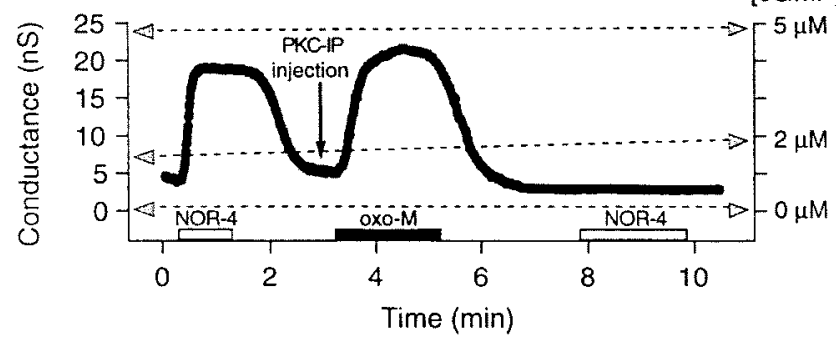

D

[cGMP]

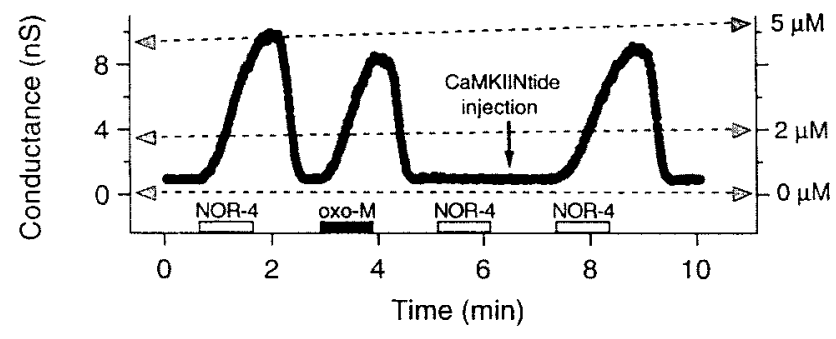

Figure 7. Effects of CaMKII inhibitors on LTS. A, Recipient neuroblastoma cells incubated with the CaMKII inhibitor KN-62 $(10 \mu \mathrm{M})$ do not exhibit the suppression of cGMP responses after oxo-M application. $B$, Injection of AIP (500 $\mu \mathrm{M}$ in injection pipette) before oxo-M application prevents the suppression of cGMP responses. $C$, Injection of PKC-IP (500 $\mu \mathrm{M}$ in injection pipette) before oxo-M application fails to prevent the suppression of cGMP responses. $D$, Injection of CaM-KIINtide (50 $\mu \mathrm{M}$ in injection pipette) after oxo-M application reverses the maintenance of LTS.

potent and selective peptide inhibitor of CaMKII (Chang et al., 1998), not only prevented induction when injected before oxo-M application (data not shown) but, when injected after oxo-M application, resulted in the reversal of LTS, restoring the NOelicited rise in cGMP to $89 \pm 7 \%(n=3)$ of the response (Fig. $7 D$ ). Hence maintained activity of CaMKII appears to be necessary for the maintenance of LTS.

\section{DISCUSSION}

\section{The mechanism of LTS}

Activation of muscarinic receptors in neuroblastoma and sympathetic neurons elevates cGMP in the short term but delayed and over a prolonged time course also suppresses the elevation of both cGMP and cAMP. The net effect is a single brief rise followed by 


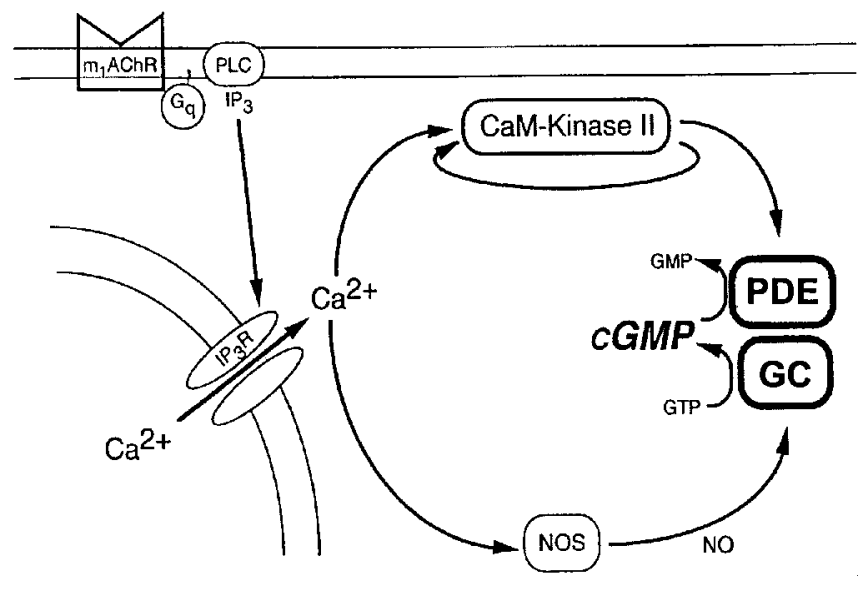

Figure 8. Diagram of muscarinic signaling cascade leading to cGMP production and long-term suppression of cGMP and cAMP. $M_{1} A C h R$, Type 1 muscarinic acetylcholine receptor; $G_{q}$, G-protein; $P L C$, phospholipase $\mathrm{C} ; I P_{3} R$, inositol triphosphate receptor; $N O S$, nitric oxide synthase; $s G C$, soluble guanylate cyclase; $P D E$, phosphodiesterase.

a nearly complete shutdown of cyclic nucleotide signaling that persists for hours. Figure 8 illustrates our proposed mechanism for the elevation and subsequent suppression of cGMP. Muscarinic receptors $\left(\mathrm{M}_{1}\right.$ subtype $)$ act via a $\mathrm{G}$-protein $\left(\mathrm{G}_{\mathrm{q}}\right)$ to activate PLC, which produces $\mathrm{IP}_{3}$. $\mathrm{IP}_{3}$ triggers $\mathrm{Ca}^{2+}$ release from storage organelles, increasing the concentration of intracellular $\mathrm{Ca}^{2+}$. $\mathrm{Ca}^{2+}$ mobilization and the resulting increase in cytoplasmic $\mathrm{Ca}^{2+}$ are necessary and sufficient for triggering both the initial cGMP signal and, with a delay, the subsequent LTS. The rise in cGMP occurs within $10 \mathrm{sec}$ after oxo-M stimulation (Trivedi and Kramer, 1998), whereas the fall in cGMP once LTS is initiated requires $>30 \mathrm{sec}$ (see Fig. $2 B$ ), consistent with LTS involving additional biochemical steps.

The $\mathrm{Ca}^{2+}$-elicited increase in cGMP involves $\mathrm{Ca}^{2+} /$ calmodulin-dependent NOS activation, production of NO, and stimulation of sGC (Christopolous and El-Fakahany, 1998; Trivedi and Kramer, 1998). The crucial $\mathrm{Ca}^{2+}$ effector involved in the longer-lasting phenomenon of LTS appears to be CaMKII. Three selective inhibitors of CaMKII (KN-62, AIP, and CaM-KIINtide) all prevent LTS induction. Induction also is prevented by BAPTA injection, consistent with a $\mathrm{Ca}^{2+}$-dependent triggering mechanism. However, once initiated, BAPTA is ineffective at reversing LTS. The observation that $\mathrm{Ca}^{2+}$ is required for inducing, but not maintaining, LTS coincides with the known behavior of CaMKII, which loses its $\mathrm{Ca}^{2+}$ sensitivity with autophosphorylation. The distinction between induction and maintenance is strikingly similar to the LTP of synaptic transmission in the hippocampus, which also involves CaMKII autophosphorylation (Malinow et al., 1988; Barria et al., 1997; Giese et al., 1998).

LTS maintenance could result from persistent CaMKII activity, leading to continual phosphorylation of PDE or other relevant substrates. In contrast, LTS might be maintained if the substrate remained stably phosphorylated, even after CaMKII activity declines. CaMKII peptide inhibitor experiments help to distinguish between these possibilities. Although AIP prevents induction, it only partly reverses the maintenance of LTS, similar to the effects of this peptide on hippocampal LTP (Otmakhov et al., 1997). However, CaM-KIINtide, a higher-affinity inhibitor, possibly more stable to intracellular degradation, does eliminate the maintenance of LTS. The observation that the maintenance of LTS can be "erased" by the injection of CaM-KIINtide suggests that CaMKII must be persistently active for LTS to endure.

Our results indicate that the enzyme that underlies LTS is PDE and not sGC. CaMKII-dependent phosphorylation of PDE, or a protein that regulates PDE activity, increases enzyme activity, severely blunting cGMP responses and reducing the resting level of cGMP. It will be interesting to identify the specific PDE(s) responsible for LTS and to determine biochemically whether they are phosphorylated directly by CaMKII. PDEs found in neuroblastoma (Giorgi et al., 1993) and sympathetic neurons (Capuzzo et al., 1986) include isoforms that are cAMP-specific (PDE-4), cGMP-specific (PDE-5), and nonspecific (PDE-1, -2, and -3) for cAMP and cGMP. Theoretically, LTS could result from augmentation of either a nonspecific PDE alone or a combination of two or more of the cyclic nucleotide-specific forms.

PDE-1 was the first enzyme shown to be activated by $\mathrm{Ca}^{2+}$ via the $\mathrm{Ca}^{2+}$ binding protein calmodulin (Cheung, 1980). Although there is strong precedent for PDE activation by increased intracellular $\mathrm{Ca}^{2+}$, this classical regulatory mechanism probably is not involved in the longer-lasting phenomenon of LTS. LTS appears to be mediated by a covalent modification of PDE, namely phosphorylation, rather than allosteric regulation by $\mathrm{Ca}^{2+} /$ calmodulin, which would disappear rapidly when $\mathrm{Ca}^{2+}$ levels decline. CaMKII phosphorylation has been shown to inhibit rather than enhance PDE-1 activity (Beavo, 1995), and our finding that vinpocetine, a selective inhibitor of this enzyme, does not elevate cGMP suggests that PDE-1 is not involved in LTS. Likewise, results with other selective PDE inhibitors suggest that PDE-2, -4, and -5 are not involved, leaving PDE-3, pharmacologically uncharacterized PDEs in other PDE families, or perhaps a novel $\mathrm{PDE}$ as the responsible enzyme.

Neurotransmitters that mobilize $\mathrm{Ca}^{2+}$, including angiotensin, bradykinin, neurotensin, and acetylcholine, can trigger LTS. However, moderate depolarization to open voltage-gated $\mathrm{Ca}^{2+}$ channels (trains of $1 \mathrm{sec}$ pulses to $0 \mathrm{mV}$ ) is ineffective in elevating cGMP or inducing LTS (our unpublished results). It is possible that there is insufficient $\mathrm{Ca}^{2+}$ influx with depolarization to trigger cGMP production and LTS induction. Furthermore, the location of the $\mathrm{Ca}^{2+}$ transient induced by mobilization, but not by depolarization, may be optimal for activating the NOS and CaMKII. Perhaps in these cells NOS and CaMKII are localized near sites of $\mathrm{Ca}^{2+}$ release (e.g., the ER) rather than near $\mathrm{Ca}^{2+}$ channels in the plasma membrane.

\section{Functional implications of LTS}

The biochemical machinery involved in cGMP production and LTS induction and maintenance is common to many cell types. The ubiquity of these proteins suggests that LTS may occur in other cells in which signals that trigger $\mathrm{Ca}^{2+}$ mobilization occur simultaneously with signals that use cGMP or cAMP, possibly providing a mechanism for long-term plasticity of transmitter interactions. It will be interesting to determine whether LTS occurs in cerebellar Purkinje neurons, in which both $\mathrm{IP}_{3^{-}}$ mediated $\mathrm{Ca}^{2+}$ release (Finch and Augustine, 1998) and NOinduced cGMP production (Lev-Ram et al., 1997) have been implicated in the long-term depression of synaptic transmission. Sympathetic neurons exhibit a form of LTP (Briggs and McAfee, 1988), and it is possible that LTS plays an important role in this process. Because cGMP and/or cAMP in sympathetic ganglia are involved in synaptic modulation (Briggs, 1992; Wu and Dun, 1996), regulation of neurotransmitter metabolism (Ip et al., 1985), 
and growth factor-mediated survival (Farinelli et al., 1996), the shutdown of cyclic nucleotide signaling also may have other important physiological consequences.

Cyclic nucleotides affect cell function via two main classes of effectors: $\mathrm{CNG}$ channels and protein kinases (PKA and PKG), which have strikingly different sensitivities to cyclic nucleotides. CNG channels are activated half-maximally by cGMP and cAMP at 2-100 $\mu \mathrm{M}$ (Zagotta and Siegelbaum, 1996), whereas PKA and PKG have apparent $K_{\mathrm{D}}$ values that range from 4 to 150 nM (Shabb et al., 1990). Our cGMP detection method is based on a highly sensitive $\mathrm{CNG}$ channel $\left(K_{1 / 2}=4 \mu \mathrm{M}\right)$, but $0.5 \mu \mathrm{M}$ is the lower limit of detection. Transmitters such as acetylcholine and NO could induce undetectable changes in cGMP concentration possibly important for regulating PKA and PKG but that are outside the range that would be important for regulating $\mathrm{CNG}$ channels. In fact, LTS may provide a mechanism for toggling the primary effectors of cyclic nucleotide signaling from channels to kinases by resetting the basal concentration and operating range of cAMP and cGMP.

There are many possible "nodes" of interaction enabling cross talk between $\mathrm{Ca}^{2+}$ and cyclic nucleotide signaling systems in cells. $\mathrm{Ca}^{2+}$, acting via calmodulin, can activate or inhibit adenylate cyclase and also activate PDE-1. More indirectly, $\mathrm{Ca}^{2+}$ affects the activity of several protein kinases and phosphatases, which can modulate receptors, G-proteins, adenylate cyclase, various PDEs, and protein kinases. By monitoring cGMP directly, we have succeeded in identifying the specific node in the signaling circuitry (CaMKII-dependent regulation of PDE) that predominates in the regulation of cyclic nucleotides in neuroblastoma cells and sympathetic neurons.

\section{REFERENCES}

Ahn HS, Crim W, Romano M, Sybertz E, Pitts B (1989) Effects of selective inhibitors on cyclic nucleotide phosphodiesterases of rabbit aorta. Biochem Pharmacol 38:3331-3339.

Albert PR, Tashjian Jr AH (1986) Ionomycin acts as an ionophore to release TRH-regulated $\mathrm{Ca}^{2+}$ stores from GH4C1 cells. Am J Physiol 251:C887-C891.

Amano T, Richelson E, Nirenberg M (1972) Neurotransmitter synthesis by neuroblastoma clones. Proc Natl Acad Sci USA 69:258-263.

Arancio O, Kandel ER, Hawkins RD (1995) Activity-dependent longterm enhancement of transmitter release by presynaptic $3^{\prime}, 5^{\prime}$-cyclic GMP in cultured hippocampal neurons. Nature 376:74-80.

Barria A, Muller D, Derkach V, Griffith LC, Soderling TR (1997) Regulatory phosphorylation of AMPA-type glutamate receptors by CaM-KII during long-term potentiation. Science 276:2042-2045.

Beavo JA (1995) Cyclic nucleotide phosphodiesterases: functional implications of multiple isoforms. Physiol Rev 75:725-748.

Beavo JA, Hansen RS, Harrison SA, Hurwitz RL, Martins TJ, Mumby MC (1982) Identification and properties of cyclic nucleotide phosphodiesterases. Mol Cell Endocrinol 28:387-410.

Briggs CA (1992) Potentiation of nicotinic transmission in the rat superior cervical ganglion: effects of cyclic GMP and nitric oxide generators. Brain Res 573:139-146.

Briggs CA, McAfee DA (1988) Long-term potentiation at nicotinic synapses in the rat superior cervical ganglion. J Physiol (Lond) 404:129-144.

Briggs CA, Horwitz J, McAfee DA, Tsymbalov S, Perlman RL (1985) Effects of neuronal activity on inositol phospholipid metabolism in the rat autonomic nervous system. J Neurochem 44:731-739.

Cahill AL, Perlman RL (1987) Preganglionic stimulation increases the phosphorylation of tyrosine hydroxylase in the superior cervical ganglion by both cAMP-dependent and $\mathrm{Ca}^{2+}$-dependent protein kinases. Biochim Biophys Acta 930:454-462.

Capuzzo A, Biondi C, Borasio PG, Ferretti ME, Fabbri E (1986) Some properties of adenosine $3^{\prime}, 5^{\prime}$-cyclic monophosphate phosphodiesterase in the superior cervical ganglion of the guinea pig. Neurochem Res 11:1425-1437.

Chang BH, Mukherji S, Soderling TR (1998) Characterization of a calmodulin kinase II inhibitor protein in brain. Proc Natl Acad Sci USA 95:10890-10895.

Cheung WY (1980) Calmodulin plays a pivotal role in cellular regulation. Science 207:19-27.
Christopolous A, El-Fakahany EE (1998) The generation of nitric oxide by G-protein-coupled receptors. Life Sci 64:1-15.

Farinelli SE, Park DS, Greene LA (1996) Nitric oxide delays the death of trophic factor-deprived PC12 cells and sympathetic neurons by a cGMP-mediated mechanism. J Neurosci 16:2325-2334.

Finch EA, Augustine GJ (1998) Local calcium signaling by inositol1,4,5-trisphosphate in Purkinje cell dendrites. Nature 396:753-756.

Forstermann U, Gorsky LD, Pollock, JS Ishii K, Schmidt HH, Heller M, Murad F (1990) Hormone-induced biosynthesis of endotheliumderived relaxing factor/nitric oxide-like material in N1E-115 neuroblastoma cells requires calcium and calmodulin. Mol Pharmacol 38:7-13.

Garthwaite J, Southam E, Boulton CL, Nielsen EB, Schmidt K, Mayer B (1995) Potent and selective inhibition of nitric oxide-sensitive guanylyl cyclase by $1 \mathrm{H}-[1,2,4]$ oxadiazolo[4,3- $\alpha]$ quinoxalin-1-one. Mol Pharmacol 48:184-188.

Giese KP, Fedorov NB, Filipowski RK, Silva AJ (1998) Autophosphorylation at Thr286 of the alpha calcium-calmodulin kinase II in LTP and learning. Science 279:870-873.

Gillespie PG, Beavo JA (1989) Inhibition and stimulation of photoreceptor phosphodiesterases by dipyridamole and M\&B 22948. Mol Pharmacol 36:773-781.

Giorgi M, Caniglia C, Scarsella G, Augusti-Tocco G (1993) Characterization of $3^{\prime}: 5^{\prime}$ cyclic nucleotide phosphodiesterase activities of mouse neuroblastoma N18TG2 cells. FEBS Lett 324:76-80.

Goulding EH, Tibbs GR, Siegelbaum SA (1994) Molecular mechanism of cyclic nucleotide-gated channel activation. Nature 372:369-374.

Holck M, Thorens S, Muggli R, Eigenmann R (1984) Studies on the mechanism of positive inotropic activity of RO 13-6438, a structurally novel cardiotonic agent with vasodilating properties. J Cardiovasc Pharmacol 6:520-530.

Horn R, Marty A (1988) Muscarinic activation of ionic currents measured by a new whole-cell recording method. J Gen Physiol 92:145-159.

House C, Kemp BE (1987) Protein kinase C contains a pseudosubstrate prototope in its regulatory domain. Science 238:1726-1728.

Hu J, El-Fakahany EE (1993) Role of intercellular and intracellular communication by nitric oxide in coupling of muscarinic receptors to activation of guanylate cyclase in neuronal cells. J Neurochem 61:578-585.

Ip NY, Baldwin C, Zigmond RE (1985) Regulation of the concentration of adenosine $3{ }^{\prime}, 5^{\prime}$-cyclic monophosphate and the activity of tyrosine hydroxylase in the rat superior cervical ganglion by three neuropeptides of the secretin family. J Neurosci 5:1947-1954.

Ishida A, Kameshita I, Okuno S, Kitani T, Fujisawa H (1995) A novel highly specific and potent inhibitor of calmodulin-dependent protein kinase II. Biochem Biophys Res Commun 212:806-812.

Kimhi Y, Palfrey C, Spector I, Barak Y, Littauer UZ (1976) Maturation of neuroblastoma cells in the presence of dimethylsulfoxide. Proc Natl Acad Sci USA 73:462-466.

Lev-Ram V, Jiang T, Wood J, Lawrence DS, Tsein RY (1997) Synergies and coincidence requirements between NO, cGMP, and $\mathrm{Ca}^{2+}$ in the induction of cerebellar long-term depression. Neuron 18:1025-1038.

Liles WC, Hunter DD, Meier KE, Nathanson NM (1986) Activation of protein kinase $\mathrm{C}$ induces rapid internalization and subsequent degradation of muscarinic acetylcholine receptors in neuroblastoma cells. J Biol Chem 261:5307-5313.

Lisman JE, Goldring MA (1988) Feasibility of long-term storage of graded information by the $\mathrm{Ca}^{2+} /$ calmodulin-dependent protein kinase molecules of the postsynaptic density. Proc Natl Acad Sci USA 85:5320-5324.

Malinow R, Madison DV, Tsein RW (1988) Persistent protein kinase activity underlying long-term potentiation. Nature 335:820-824.

Mathes C, Thompson SH (1994) Calcium current activated by muscarinic receptors and thapsigargin in neuronal cells. J Gen Physiol 104:107-121.

Mery PF, Pavoine C, Pecker F, Fischmeister R (1995) Erythro-9-(2hydroxy-3-nonyl)adenine inhibits cyclic GMP-stimulated phosphodiesterase in isolated cardiac myocytes. Mol Pharmacol 48:121-130.

Moolenaar WH, Spector I (1978) Ionic currents in cultured mouse neuroblastoma cells under voltage-clamp conditions. J Physiol (Lond) 278:265-286.

Nicoll RA, Malenka RC (1995) Contrasting properties of two forms of long-term potentiation in the hippocampus. Nature 377:115-118.

Otmakhov N, Griffith LC, Lisman JE (1997) Postsynaptic inhibitors of calcium/calmodulin-dependent protein kinase type II block induction but not maintenance of pairing-induced long-term potentiation. J Neurosci 17:5357-5365.

Shabb JB, Ng L, Corbin JD (1990) One amino acid change produces a high affinity cGMP-binding site in cAMP-dependent protein kinase. J Biol Chem 265:16031-16034.

Silva MT, Rose S, Hindmarsh JG, Aislaitner G, Gorrod JW, Moore PK, Jenner P, Marsden CD (1995) Increased striatal dopamine efflux in vivo following inhibition of cerebral nitric oxide synthase by the novel monosodium salt of 7-nitro indazole. Br J Pharmacol 114:257-258.

Tanner LI, Harden TK, Wells JN, Martin MW (1986) Identification of 
the phosphodiesterase regulated by muscarinic cholinergic receptors of 1321 N1 human astrocytoma cells. Mol Pharmacol 29:455-460.

Thompson SH, Mathes C, Alousi AA (1995) Calcium requirement for cGMP production during muscarinic activation of N1E-115 neuroblastoma cells. Am J Physiol 269:C979-C985.

Tokumitsu H, Chijiwa T, Hagiwara M, Mizutani A, Terasawa M, Hidika $\mathrm{H}$ (1990) KN-62, 1-[N,O-bis(5-isoquinolinesulfonyl)- $N$-methyl-L-tyrosyl]4-phenylpiperazine, a specific inhibitor of $\mathrm{Ca}^{2+} /$ calmodulin-dependent protein kinase II. J Biol Chem 265:4315-4320.

Trivedi B, Kramer RH (1998) Real-time patch-cram detection of intracellular cGMP reveals long-term suppression of responses to NO and muscarinic agonists. Neuron 21:895-906.
Wotta DR, Parsons AM, Hu J, Grande AW, El-Fakahany EE (1998) M1 muscarinic receptors stimulate rapid and prolonged phases of neuronal nitric oxide synthase activity: involvement of different calcium pools. J Neurochem 71:487-497.

Wu CC, Ko FN, Kuo SC, Lee FY, Teng CM (1995) YC-1 inhibited human platelet aggregation through NO-independent activation of soluble guanylate cyclase. Br J Pharmacol 116:1973-1978.

Wu SY, Dun NJ (1996) Potentiation of IPSCs by nitric oxide in immature rat sympathetic preganglionic neurones in vitro. J Physiol (Lond) 495:479-490.

Zagotta WN, Siegelbaum SA (1996) Structure and function of cyclic nucleotide-gated channels. Annu Rev Neurosci 19:235-263. 